\title{
IT STRATEGIES FOR DEVELOPMENT OF HEALTH TOURISM
}

\author{
Amir Abbas Farahmand \\ Master of IT Management Ferdowsi University of Mashhad
}

Ehsan Merati

$\mathrm{PhD}$ in Information Technology Management, Assistant Professor University of Ferdowsi Mashhad

\begin{abstract}
Given that tourism is the largest industry for income in the world in some countries, more attention to it seems quite logical. In recent years information technology practice has evolved all organizations, particularly the tourism industry. Appropriate benchmarking of countries that already have good ratings in the world in the industry in terms of number and in terms of income, Can shorten and optimize the path of success as much as possible and. In this regard, the role of the Internet in the era of globalization is very important, hence the use of this technology is highly regarded for tourism that in this study we examine the strategies and challenges. Therefore with referring to health centers of Razavi and Imam Reza in Mashhad, and statistical information on how to get familiar with these centers, from clients residing abroad and analysis of this data were examined with spss software. And indicators effective in getting information by patients from the medical center were determined. Results showed that the most use from the Internet was by personal computers and mobile phones, respectively.
\end{abstract}

Keywords: health tourism, information technology, IT

\section{INTRODUCTION}

One of the advantages of globalization in recent years were web development and significant impact of information and communication technology on the performance of different organizations. Due to the potential that information and communication technology has in the business demands, constantly efforts were made to develop its infrastructure and its applications in different fields. However, these capabilities has led ICT to be seen not only as a facilitating tool, but also as a powerful organizational tool, in order to reach the targets. One area that has recently been used to develop the infrastructure of ICT in the country, is the field of tourism. In the meantime e-tourism as one of the main applications of e-commerce is vital. One of the areas that have been affected by web development is medical tourism or health tourism. Today, the subject of treatment in developing countries has improved, globalization and liberalization of trade in health services is context of the rapid growth of this type of tourism [1] medical tourism, is an organized trip of one's environment to another place in order to keep improving and restoring the individual's physical and mental health [2]. Travel for treatment and recovery is the most important objectives of medical tourism, medical and often revolve around health services, leisure activities is also added to patients' health package [3]. Since current economic situation and the life problems are the main reasons affecting the high stress level of people's lives, medical tourism is a choice for those considering the health and welfare of their health, going away from your everyday stressful life with the development of health tourism can be used as a national strategy, in addition to the efficient use of internal resources in order to increase the country's income as an arm of national security Medical tourism market is presented as a profitable and competitive industry all over the world and is new developed area of tourism. At the macro level, governments want to enjoy the economic benefits of the industry and hence increased competition between different countries, especially developing countries in Asia to attract health tourists is started [4,5]. On the other hand with the development of web-browsing tools, physical boundaries between in the field of health tourism is gone and health tourists seeking to achieve a higher level of service in the all parts of the world. One of the things that in area has a very high importance is the management approach to marketing. So has provided health facilities to tourists before departure to a country, obtain information from welfare services and medical facilities to select 
the right decision to take treatment. Therefore, identification of Effective Parameters in people's decisions and create opportunities to respond to them have always been among the goals of organizations to provide services in the field of destination marketing. Accordingly in this study, according to marketing applications and importance of medical tourism, we will continue to identify and prioritize each of the parameters that influence the choice of destination by persons.

\section{THE HISTORY OF MEDICAL TOURISM:}

The concept of medical tourism is not new, but the history goes back thousands of years, when Greek pilgrims went to the holy place known as "Apydvrya" on the Saronic Gulf for taking healing and their treatment from Slkpyvs God of peace. In this place also there were professionals who were paid to care and treatment for people, in the UK during the rule of the Roman Empire for two thousand years, people referred to shrines where they wash themselves in holy water. In the 18th century also wealthy Europeans and especially Germans tended to travel along the Nile for their peace and health. At present, many countries have focused on health tourism and the important thing is that patients in addition to benefiting from the treatment also enjoy the country's tourism attractions. Generally effort were made that patients stay in a good and standard hotels close proximity to medical centers and hospitals and benefit from a high level of welfare services and interpreters in a hospital or hotel.

\section{THE ROLE AND IMPACT OF INFORMATION TECHNOLOGY IN MEDICAL TOURISM:}

Today the role and impact of ICT and tourism industry on economic growth is no secret. Using the Internet and the creation of e-tourism and ICT, is considered one of the basic tourism elements and has increased the efficiency of this industry. The main purpose of this paper, to evaluate the impact of tourism on economic growth due to the role of information and communication technology, and second, to explain the factors affecting tourism, including GDP per capita, spending on information and communication technology, the degree openness of the economy, human capital and per capita education spending. Tourism system contains five basic areas of origin, travel route, destination, tourism industry and external environment [14]. ICT is one of the basic elements of the external environment in tourism and travel. ICT is an essential partner that establish relationship between consumers and producers on a global scale. On the other hand, tourism is an information-based activities. Variable intangible services and tourism variable, cannot be physically inspected before sail and goods are purchased normally before the time of consumption and away from consumption locations. The tourism product is highly dependent on the introduction and description and the information are provided in the form of written, audio and video. Thus, the separation of information and communication technology, including transfer tool information and communications, including fixed phones, mobile phone, service, wireless, Internet, global positioning system, geographical information system, the destination management of tourism industry is impossible. One of the points regarding the relationship between ICT and tourism form, is their bilateral relationship. Needs of tourism industry to IT, according to the development needs of consumers and new methods to facilitate growing is developing. On the other hand, the development of information technology provide tools and additional functionality to meet the needs of the industry. This process is like a path in which one part cause the development of other sectors and accelerate their movement to forward. Continuous development of information and communication technology during the past two decades, had deep application in tourism industry.

\section{THE DEBATE ON MEDICAL TOURISM IN THE WORLD}

A combination of several factors stimulate the increasing growth tendency of people to medical tourism, including: high cost of living in industrialized countries, facilitating international travel and improve the level of technology and medical standards in many countries of the world. Due to tendency to medical travel, the comfort is compared with other countries. In some countries where public health care system are common too much time is spent to respond to the needs of citizens and patients have to spend a long time waiting for them to deal with their condition, such as hip transplant that they should be at the turn of wait for a year or more in the UK and Canada. But in Singapore, Thailand, Philippines, and Bangalore India, a patient can be cared and treated one day after arrival. Of the reasons that make people travel with their treatment goal are, low cost medical care, the search for a specialist and experienced, good quality health care, safety and shorter waiting time for 
treatment. In Canada, in 2005 the number of people waiting for treatment, was 782,936 that was a record in the world. The number of people in South Africa, is less than one tenth which is lower than the United States or Western Europe. A heart valve transplant costs about 200 thousand dollars and even more, in the United States while Bridge metal teeth is \$ 5,500 in America, in Bolivia, India is \$ 500 and in Philippines, is $\$ 200$ is and so, the cost of eye transplant in Thailand with 6 days physical therapy is about one-fifth of the United States and LASIK eye costs \$3,700 in the United States, that in many countries, medical tourism approach is about 730 dollars. Moreover, while for cosmetic surgery in the United States may make about 20 thousand dollars while in countries such as South Africa, the Philippines, and Bolivia is between 2300 to 2700 dollars. Tourists seeking health care anywhere in the world can enter the country and be under medical care in the fields of: cancer, neurological diseases, organ transplant surgery, cosmetic surgery, etc. Among the countries that are open to tourists, could name countries such as: Brunei, Cuba, Hong Kong, Hungary, India, Israel, Jordan, Lithuania, Malaysia, the Philippines, Singapore, Thailand and most recently the United Arab Emirates (Dubai) and named. The countries in the field of cosmetic surgery is considered mainly: Argentina, Bolivia, Brazil, Costa Rica, Mexico and Turkey, in Europe, Belgium and Poland that are engaged to businesses in medical tourism. Interestingly, South Africa with the slogan of "cosmetic surgery together with seeing wildlife" tries to attract medical tourists. In countries such as the United States, with insurance services and its high-quality treatment, addressing business in medical tourism is considered a risk. Mentioning an example is enough to show that the reason for this approach in the United States and that is shift of large number of patients in the Middle East in 2006, who preferred to seek treatment to Hong Kong and Singapore. To know the medical tourism condition in several hub of this business in the world, we study them.

\section{MEDICAL TOURISM IN IRAN:}

Health tourism in our country could have a special place. There are equipped hospitals, qualified physicians and experienced nurses who can assist promoting it. What is certain, sincere cooperation between Cultural Heritage and other relevant bodies will accelerate this trend. Four Seasons Nature in Iran with warm and mineral water, the staff step in research and standardization of them quickly and will promote Position of the field of tourism industry to other fields. Movement of "Staff health tourism" in the organization of cultural heritage in both directions of attracting foreign patients with extensive advertising and investment in different parts of the research and training, creating health Centers, clinics for check-ups, with centers of both modern and traditional on-site of hot springs and suitable information, are the ways that reduce The departure of citizens abroad for treatment, thereby prevents leaving a large amount of currency in the year Studies show that approximately one billion dollars goes out the country by the people. staff activities in these fields requires facilities, that in case of a supply by the relevant authorities in horizon of 1400 of the field of the tourism industry is seen very bright and realizable Therefore, Iran will be one of the Main poles of health tourism in the region through which decreases the level of outflow of currency. But considerable revenues will accrue to the country. This policy can provide the context of employment and investment.

\section{THE PROBLEMS AND RISKS OF MEDICAL TOURISM:}

Among the factors that can lead to increased risk of medical travel include:

1. Lack of strong insurance coverage is in some countries.

2. There are a number of communicable diseases in countries such as India, Thailand, Malaysia and Costa Rica

3. Travel after surgery and complications can have serious hazards.

4. Long journeys to access to medical services in other countries may be dangerous for some patients.

\section{MATERIALS AND METHODS:}

This study based on purpose, is descriptive and correlational type and research is functional and is cross-sectional study that the method is descriptive-correlation. Data collection methods generally include two categories, libraries method and methods of a field - questionnaire. In this study on collecting data related to test hypotheses, mainly field interview method is used and to collect information about the literature, library research is used (read books, articles, magazines, research 
projects and databases library). The results are arranged in separate tables and using skewness, kurtosis and Shapiro Wilk data normalization was carried out to identify parametric or nonparametric of them. After determining the type of statistical test, analysis was performed and results were extracted. This study was done in 2014-2015. Studies spatially have been done in the city of Mashhad. Since this study was conducted in form field, research tool, is the interview of health tourists of Imam Reza and Razavi in Mashhad. Interview questions are consisted of the public and special sector. Public sector includes five questions about gender, marital status, age, education level, which is used for data analysis. In special section, all the questions were asked to assess causal relationships between the impacts of electronic marketing to attract health tourists.

\section{FINDINGS:}

Required data of research were collected from interviews with 30 health tourists, which contains questions on demographic information and questions related to the hypothesis of the research. To analyze the collected data, descriptive statistics is first study that examine the demographic variables, as well as explanations and descriptions of variables. Test data on research, frequency and percent of participants in terms of age, can be seen in Table 1. And other shows that of the 30 cases, $20 \%$ of the sample $(n=6)$ was between $35-20$ years, $33.3 \%$ of the sample $(n=10)$ was between $55-36$ years, $16.7 \%$ of the sample (5 persons) was between $56-60$ years and $30 \%$ of the sample $(n=9)$ was higher than 61 years (Figure 1 and 2).

Table 1. Descriptive analysis of the respondent's age

\begin{tabular}{cccc}
\hline age & frequency & percent & The cumulative percentage \\
\hline 20-35year & 6 & 20 & 20 \\
36-50year & 10 & 33.3 & 53.3 \\
51-65year & 5 & 16.7 & 70 \\
Higher than 66 & 9 & 30 & 100 \\
total & 30 & 100 & \\
\hline
\end{tabular}

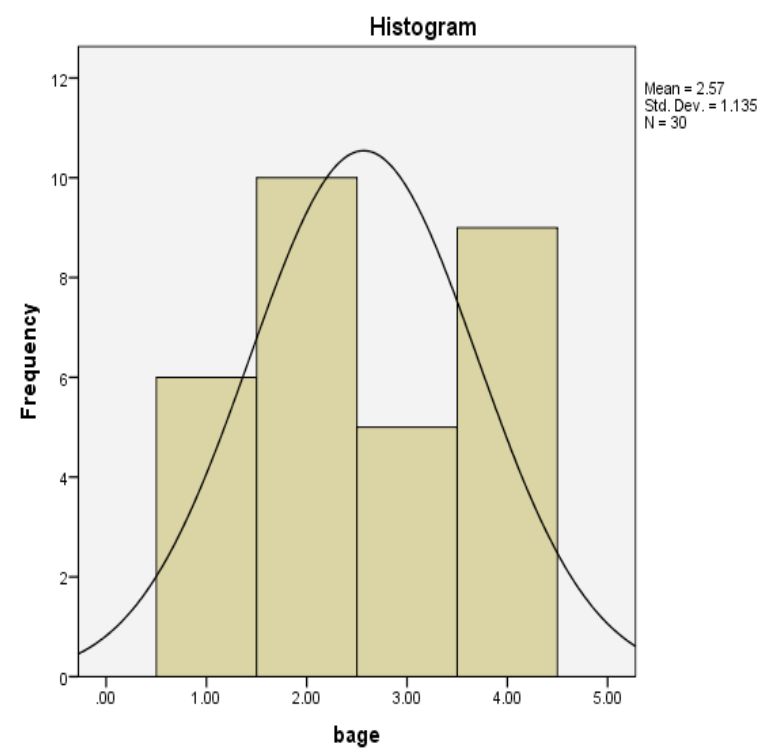

Figure 1- descriptive histogram of participants 


\section{THE DATA ANALYSIS RELATED TO GENDER:}

The next test, was on research data, frequency and percentage of people participating in the test in terms of gender, is in Table 2 that shows of the 30 patients, $53.3 \%$ of the sample $(n=16)$ were male and $46.7 \%$ of the sample (14) are women.

Table 2 shows the distribution of the sample by gender

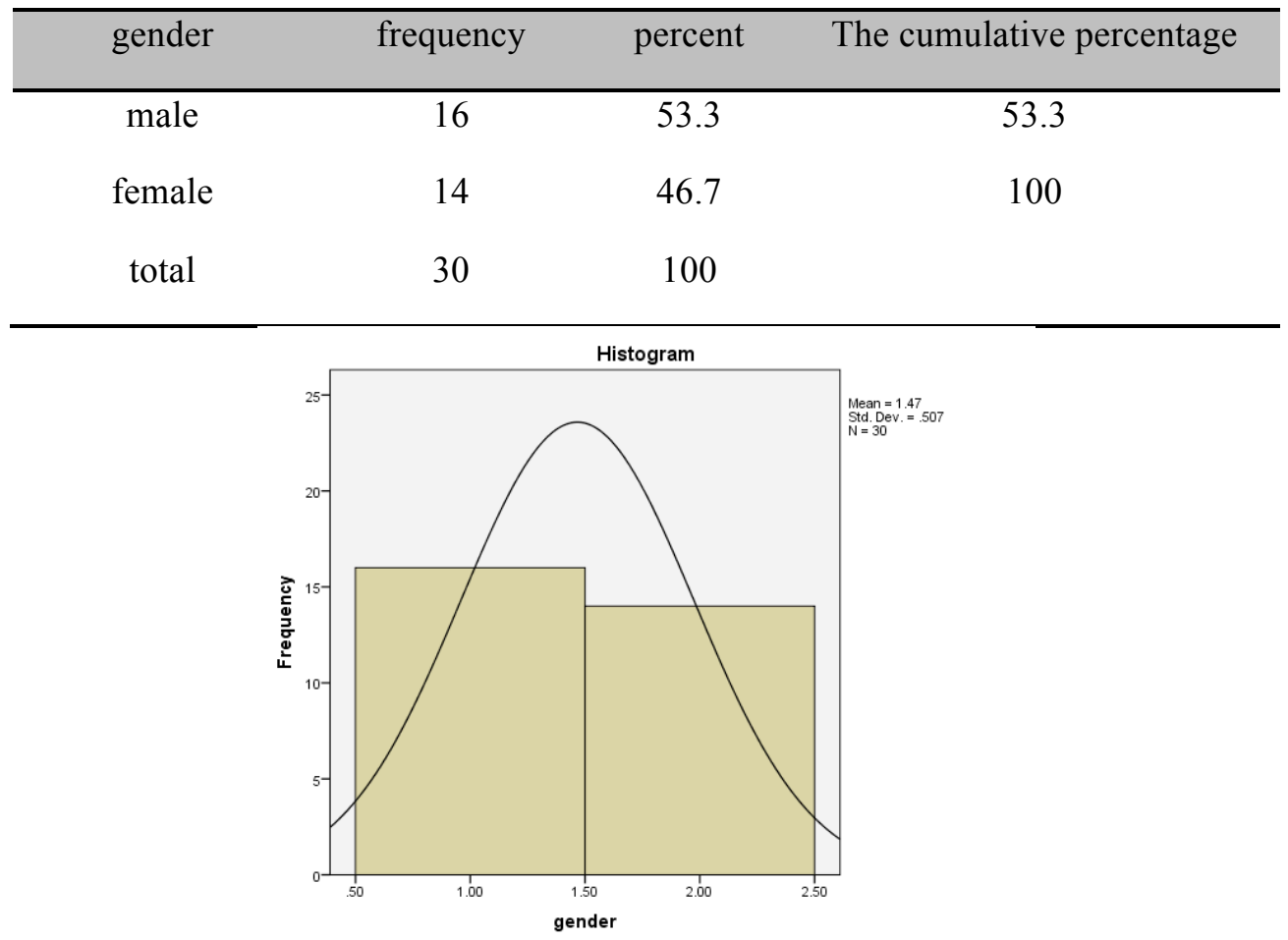

Figure 2 the histogram of gender description

\section{STUDY INTRODUCTION TO THE HEALTH TOURISM AND THE ROLE OF IT IN CREATING INTEREST IN HEALTH TOURISM:}

\section{acquaintance with the health tourism and the role of IT:}

Table 3 shows that of the 30 patients, $23.3 \%$ of the sample $(n=7)$, through e-mail and $30 \%$ of the sample $(n=9)$ through websites such as internet forums, news sites, site hospital and $23.3 \%(7 n)$ by mobile apps and $23.3 \%(n=7)$ through acquaintances and friends were familiar with medical centers.

Table 3: Distribution of the sample according to the acquaintance

\begin{tabular}{cccc}
\hline Type of relationship & frequency & percent & $\begin{array}{c}\text { Cumulative } \\
\text { percent }\end{array}$ \\
\hline Email & 7 & 23.3 & 23.3 \\
\hline
\end{tabular}


The Turkish Online Journal of Design, Art and Communication - TOJDAC July 2016 Special Edition

\begin{tabular}{cccc}
\hline Websites & 9 & 30 & 53.3 \\
Mobile apps & 7 & 23.3 & 76.6 \\
$\begin{array}{c}\text { acquaintances and } \\
\text { friends }\end{array}$ & 7 & 23.3 & 100 \\
total & 30 & 100 & \\
\hline
\end{tabular}

-analyze the data related to the devices used:

Descriptive analysis of tools used by the respondents are shown in following tables and graphs

Table-descriptive analysis of tools used by respondents

\begin{tabular}{ccc}
\hline tool & frequency & percent \\
\hline laptop & 8 & 26.7 \\
Mobile phone & 7 & 23.3 \\
$\begin{array}{c}\text { acquaintances and } \\
\text { friends } \\
\text { travel agencies }\end{array}$ & 7 & 23.3 \\
total & 8 & 26.7 \\
\hline
\end{tabular}

\section{CONCLUSION}

Today, tourism in many countries, is the main force of the country's economic recovery and growth, and is one of the most dynamic economic activities of our time that plays an important role in local sustainable development. In fact, with the launch and development of this industry and a strategic opportunity is created to diversify the economy, job creation and income. In the meantime, health tourism, as one of the types of tourism, is an important position in terms of revenue, because Health is the First and foremost gift that God has bestowed upon mankind and always under all circumstances make efforts to benefit from the best features of this area, Thus, with regard to the role of health tourism in the income and the importance of health for individuals, In this study, we discussed the role of information technology in health tourism and for this purpose, foreign tourists of Imam Reza (AS), Razavi were interviewed for their acquaintance. The results are as follows:

1. According to table 1 of 30 patients, $20 \%$ of the sample were between $35-20$ years, $33.3 \%$ of the sample were between $55-36$ years, $16.7 \%$ were between $56-60$ years and $30 \%$ of the sample of the sample were statistically higher than 61 years. This reflects the fact that most patients are between 36 and 55 years of age and persons are living in their middle age

2. According to table 2 , of the 30 patients, $53.3 \%$ of the sample were men and $46.7 \%$ of the sample are women.

3. According to table 3 , of the 30 patients, $23.3 \%$ through e-mail and $30 \%$ of the sample through websites such as internet forums, news sites, site hospital, and 23.3 through mobile apps through and $23.3 \%$ became familiar with acquaintances and friends with medical centers. Thus, as noted, the findings show that about $76.7 \%$ of the patients admitted to the hospital, became familiar with medical center through the means of communication. In other words, most people are using tools such as 
mobile apps, internet forums, news sites, hospital site and e-mail and only $23.3 \%$ became familiar with medical center through acquaintances, friends. Which indicates the role of IT in attracting tourists to the hospital's health. Thus by suitable investment in this sector, outside the hospital income is increased and high medical services, gave new life to medical centers, However, this should not be done at the expense of low services for domestic patients, because most public hospitals have been built with costs and public budgets and costs and the main purpose of the construction in the first stage, is treatment, care and support for domestic patients.

\section{REFERENCES}

Mirzaee Ghale, Farzad Ahmad MALEKAN and Mohammad Javad Butcher, 2013, clarifying the role of information technology in the development of tourism, geography fourth National Student Conference, Tehran

Tabibi Seyyed Jamal al-Din al-Nasiri, Amir Ashkan, Ayyubian Ali Bagherian, Mahmoud Abadi Hossein. Mechanisms for informing and attracting medical tourists in hospitals in Tehran. Health Information Management 2013, 416-423

Carrera P, Bridges J. Health and medicaltourism: What they mean and imply for health care systems? In: Merz F, editor .New York: Hanser Verlag; 2008

Caballero SD, Mugomba C. Medical tourism and its entrepreneurial opportunities: A conceptual framework for entry to the industry [dissertation]. Sewden: Goteborg University; 2006.

Vajira Kachorn T. Implementation of an effective health tourism development plan of Thailand [dissertation]. Thailand: University of Wisconsin-Stout; 2004

Rokni, Laden, Mohammad Bagher Rokni, Ahmad Ahmad Pour Ahmed Mehdi Rezaei, 2010, review of health tourism In the island country in the Persian Gulf-based health needs assessment, the Sixth National Conference on Cultural Tourism The Persian Gulf, Tehran, scientific tourism center cultural Forum,

Lotfi, doctor Haidar and Leila Zarei, 2013, health tourism (with an emphasis on the exploitation of the salt cave salt island), the first national conference on tourism, geography and environmental sustainability, Hamedan, Community Environmental Assessment Hegmataneh

Mohammadi Nejad, Soodeh, Reza Ismaili and Esa Jokar Sarhangi, 2013, the capacity of health tourism survey from the perspective of tourists (Case Study spa village Larijan), the first national conference on tourism, geography and environmental sustainability, Hamedan, Community Environmental Assessment Hegmataneh

Jafari, Hassan, Elham Bakhtiari and Mina Keshtkar, 2011, medical tourism and its importance in the health system of Iran, First International Conference on Tourism Management and Sustainable Development, Shiraz, Islamic Azad University of Shiraz.

Azani, Mehdi, Hassan Setayeshi and Narges Zare Pisheh, 2011, hot springs - the city Sareyn capabilities in the field of medical tourism, the first international conference on tourism management and sustainable development, Shiraz, Islamic Azad University of Shiraz.

Rajabi, Azita, Afshin cashier Mina Torabi and Roozmehr Ranjbarrad, 2011, the impact of information and communication technologies in the tourism industry, First International Conference on Tourism Management and Sustainable Development, Shiraz, Islamic Azad University of Shiraz.

Rajai Mohammad Ali Mohsen Mohammad Khani and Hamideh Ahadzadeh, 2011, the capacity of health tourism in the globalization process development of sustainable tourism, conference tourism and sustainable development, Hamedan, Islamic Azad University, Hamedan

Memarzade, Gholamreza., Mehrzad Sarafrazi and Samaneh Fayez, 2012, approach information technology (IT) in the development of electronic tourism, the first National Conference on Geography and Tourism in the third millennium, Najaf Abad, Islamic Azad University of Najaf Abad

Pourfaraj Alireza, Esazadeh Rshan Yoosef, Cheraghi Cobra, ICT, tourism industry, economic growth, economy and new business: Summer 2008, Volume 4, Number 13; From page 46 to page 66.

Quah, D. (2003). Digital goods and the new economy. Center for Economic performance, London School of Economics and political science

Gilbert, C., \& Pfister, C. (2001). The Challenges of the new economy for Monetary Policy'. Bank of France

Global Market Insite. (2005). Survey of 18000 consumer Globally .Jon 